\title{
Small bowel adenocarcinoma diagnosed by double balloon enteroscopy in a patient with nonpolyposis colorectal cancer
}

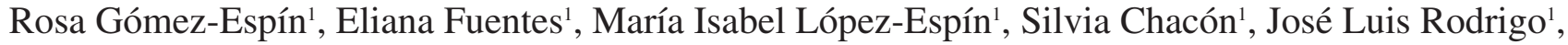 \\ Pilar Esteban ${ }^{1}$, Antonio López-Higueras ${ }^{1}$, Antonio Albarracín ${ }^{2}$, Joaquín Molina ${ }^{3}$ \\ and Enrique Pérez-Cuadrado ${ }^{1}$
}

${ }^{\prime}$ Department of Digestive Diseases. Hospital Morales Meseguer. Murcia, Spain. ${ }^{2}$ Department of General and Digestive Surgery. Hospital Reina Sofía. Murcia, Spain. ${ }^{3}$ Department of Digestive Diseases. Hospital Virgen de la Arrixaca. Murcia, Spain

\section{CASE REPORT}

A 56-year-old woman with positive genetic testing of hereditary nonpolyposis colorectal cancer (HNPCC), many familiar history of different neoplasia (Fig. 1), and a personal history of hysterectomy due to an endometrial cancer was referred to our Unit because of anemia with a positive fecal occult blood test. Both, gastroscopy and colonoscopy were performed with the only result of less than 10 hyperplastic colonic polyps without signs of recent bleeding. An abdominal CT was also performed and was completely normal. According to these results, it was indicated a capsule endoscopy that showed a stenotic polypoid lesion near of the Treitz angle. The capsule stayed retained and its battery went off at this point. With the objective of making a histological diagnosis and removing the capsule endoscopy, a double balloon endoscopy was performed, and

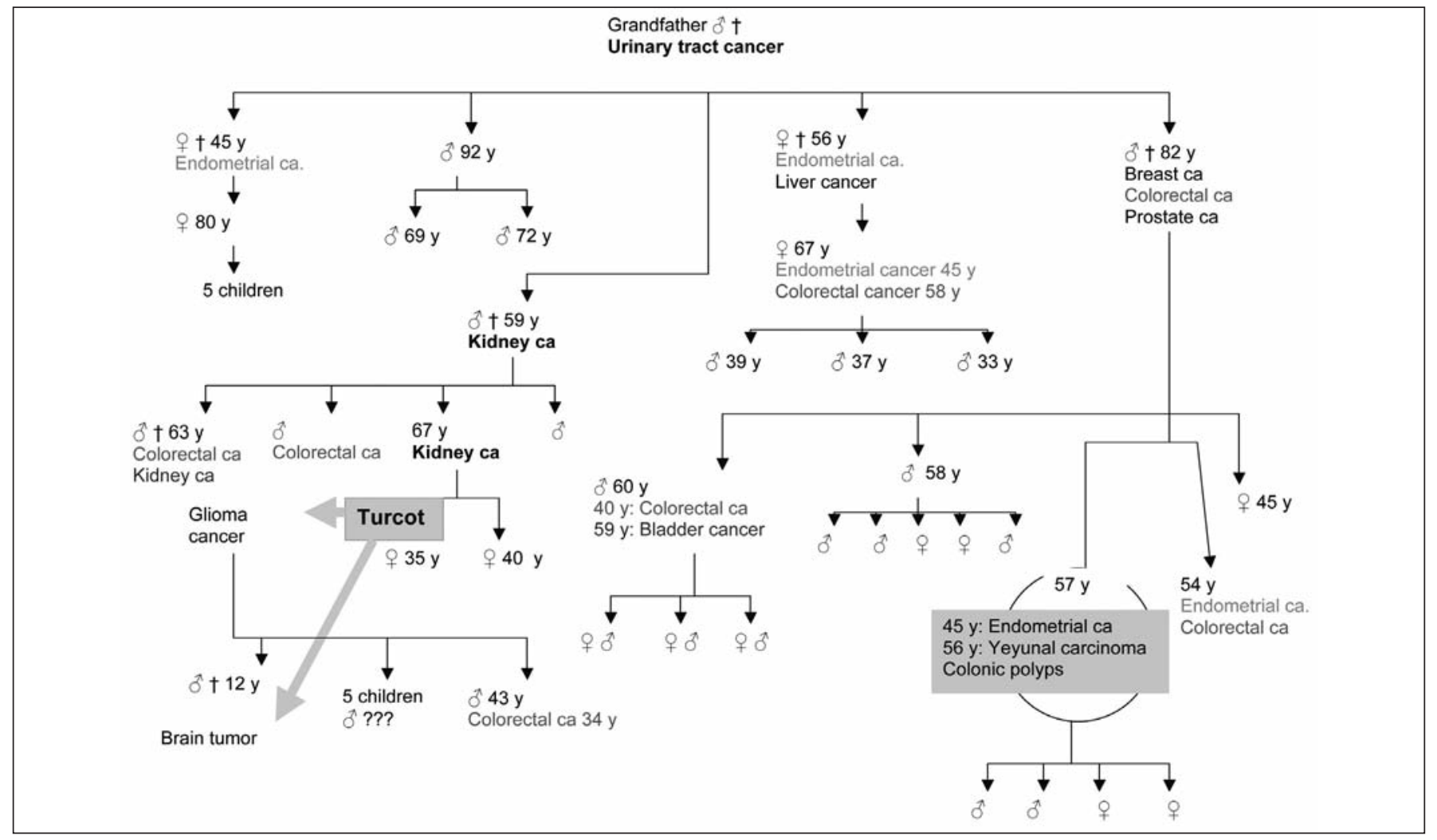

Fig. 1. Family tree. 


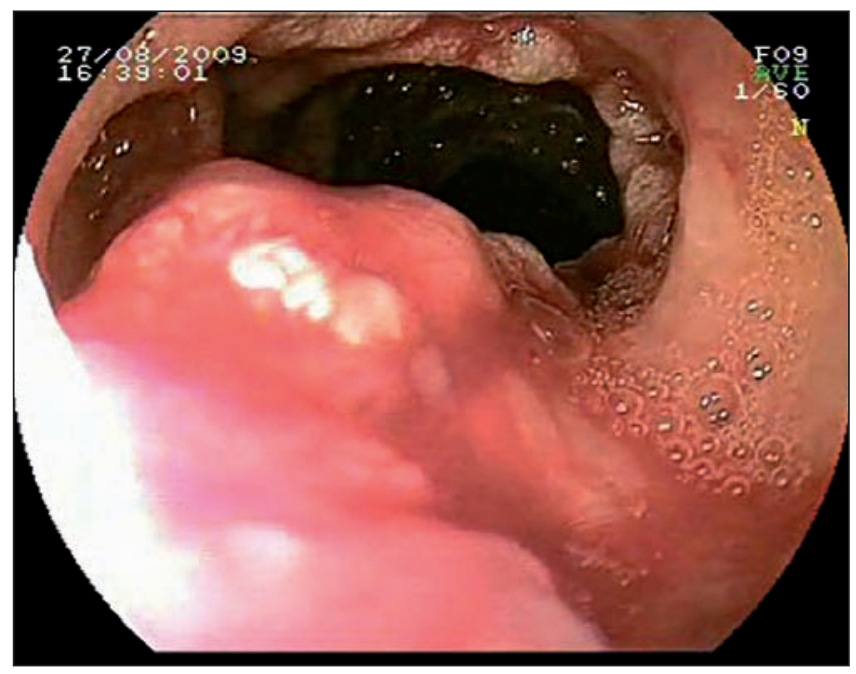

Fig. 2. Stenotic polypoid lesion near of the Treitz angle during DBE.

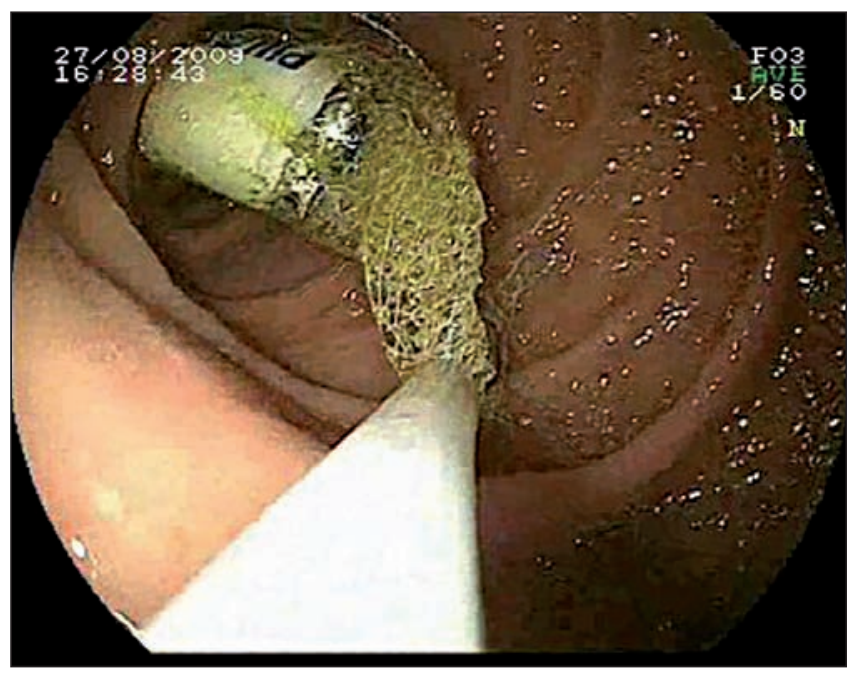

Fig. 3. Capsule endoscopy withdrawal.

the CE retention in a stenosis was confirmed (Fig. 2). The CE was recovered (Fig. 3). The histological study showed small bowel adenocarcinoma, and the surgical resection confirmed a villous adenoma with adenocarcinoma areas.

\section{DISCUSSION}

The risk of developing a small bowel adenocarcinoma in patients with hereditary nonpolyposis colorectal carcinoma is a hundred times higher than healthy population (1). The main location is in duodenum in general population whereas in these patients it can appear in any segment of small bowel, in younger people and with better prognostic. Small bowel adenocarcinoma has been described in patients with genetic mutation of MLH1 and MSH2 whereas it has not been reported in patients with mutation of MSH6 (2).

Therefore, we propose to perform a SB screening with CE in patients with HNPCC and MLH1 or MSH2 genetic mutation (3). In case the capsule showed some kind of lesion, we will be able to perform a guided DBE which is a first-line method of small-bowel exploration that complements capsule endoscopy (4).

\section{REFERENCES}

1. Rodriguez-Bigas MA, Vasen HF, Lynch HT, Watson P, Myrhoj T, Järvinen HJ, et al. Characteristics of small bowel carcinoma in hereditary nonpolyposis colorectal carcinoma. International Collaborative Group on HNPCC. Cancer 1998;83(2):240-4

2. Kate GL, Kleibeuker JH, Nagengast FM, Craanen M, Cats A, Menko FH, et al. Is surveillance of the small bowel indicated for Lynch syndrome families? Gut 2007;56(9):1198-201.

3. Marmo R, Rotondano G, Riccio G, D Angella R, Rescinito M, Rescinito A, et al. Small Bowel adenocarcinoma diagnosed via capsule endoscopy in a patient found to have hereditary nonpolyposis colorectal cancer. Gastrointest Endosc 2007;65(3):524-5.

4. Pérez-Cuadrado E, Esteban P, Shanabo J. Enteroscopia oral hasta ciego. Rev Esp Enferm Dig 2007;99(6):351. 